\title{
Redescription of the gonad-infecting nematode Philometra saltatrix Ramachandran, 1973 (Philometridae) based on specimens from the type host Pomatomus saltatrix (L.) (Osteichthyes) from the Tuscan Sea, Italy
}

\author{
František Moravec ${ }^{1},{\text { Marta } \text { Magi }^{2} \text { and Fabio Macchioni }}^{2}$ \\ ${ }^{1}$ Institute of Parasitology, Biology Centre of the Academy of Sciences of the Czech Republic, Branišovská 31, 37005 České \\ Budějovice, Czech Republic; \\ ${ }^{2}$ Dipartimento di Patologia Animale, Profilassi ed Igiene degli Alimenti, Università di Pisa, Viale delle Piagge 2, 56124 Pisa, \\ Italy
}

Key words: Philometra, parasitic nematode, gonads, marine fish, Pomatomus, Italy

\begin{abstract}
The philometrid nematode, Philometra saltatrix Ramachandran, 1973, is redescribed from male and female specimens collected from the ovaries of the marine fish (bluefish) Pomatomus saltatrix (L.) (Pomatomidae, Perciformes) from the Tuscan Sea, Italy. The light and scanning electron microscopical examination made it possible to study in detail the morphology of this so far little known species. For the first time, the actual structure of the male cephalic and caudal ends is described. The male possesses 14 small cephalic papillae arranged in two circles, the spicules are 84-111 $\mu \mathrm{m}$ long and the gubernaculum, 75-84 $\mu \mathrm{m}$ long, has its distal portion provided with dorsal transverse lamella-like structures. The caudal end of subgravid females bears two very small, hardly visible lateral papilla-like projections. This is the first record of $P$. saltatrix, a species originally described from the West Atlantic, from the Tuscan Sea and the second one in the Mediterranean region.
\end{abstract}

Dracunculoid nematodes of the genus Philometra Costa, 1845 parasitizing the gonads of many species of marine fishes are widely distributed in the Atlantic, Indian and Pacific Oceans (Moravec 2006). Because of difficulties in studying these nematodes associated with their morphological and biological peculiarities (Rasheed 1963, Moravec 2004), these parasites, as most other philometrids, remain poorly known. They may cause serious damage to the fish ovaries and may thus affect fish reproduction of wild or cultured fish hosts of economic importance (Ramachandran 1975, Hine and Anderson 1982, Sakaguchi et al. 1987, Clarke et al. 2006, Moravec and Salgado-Maldonado 2007) and, therefore, their correct species identification is very important.

Philometra saltatrix Ramachandran, 1973 was inadequately described by Ramachandran (1973) from the gonads of the bluefish, Pomatomus saltatrix (Linnaeus) (Pomatomidae, Perciformes), off the Atlantic coast of the USA (Connecticut). However, the original description contains some inaccuracies and evident errors. Further, some important taxonomic features were not provided (see Moravec and Genc 2004), and the type specimens were not deposited. In North America (Northwest Atlantic, USA: off New York, North Carolina and South Carolina), $P$. saltatrix was later recorded from Pomatomus saltatrix by Cheung et al. (1984), Clarke et al. (2006) and Moravec et al. (2008), but no parasite description was given. Although Moravec and
Genc (2004) described subgravid females of $P$. saltatrix from the gonads of $P$. saltatrix from the Mediterranean Sea (Iskenderun Bay) off the coast of Turkey, many important morphological features of this species have remained unknown to date.

During recent investigations into the parasites of $\mathrm{PO}-$ matomus saltatrix of the Tuscan Sea, Italy, carried out by the Italian authors of this paper, the ovaries of this fish were frequently found to be infected with Philometra saltatrix. This material enabled to re-study, including the use of scanning electron microscopy (SEM), this little-known Philometra species, and to redescribe it. The results of this study are presented herein.

Bluefish $P$. saltatrix (maximum body length $130 \mathrm{~cm}$, weight up to $14.4 \mathrm{~kg}$ ) is an important commercial fish and gamefish, and is also utilized for aquaculture; it has a circumglobal distribution in tropical and subtropical waters (Froese and Pauly 2008).

\section{MATERIALS AND METHODS}

A total of 500 specimens (200 males and 300 females) of bluefish Pomatomus saltatrix was collected along the Tuscany coast, Italy in 2006; their total body lengths were mostly 30 $60 \mathrm{~cm}$, with a maximum of $78 \mathrm{~cm}$. The fish were transported on ice to the parasitological laboratory of the Veterinary Faculty in Pisa and immediately examined for the presence of parasites. The nematodes were dissected out of the gonads (mainly ovaries) of fresh fish and, after being washed in physiological saline, they were fixed and stored in $70 \%$ etha-

Address for correspondence: F. Moravec, Institute of Parasitology, Biology Centre of the Academy of Sciences of the Czech Republic, Branišovská 31, 37005 České Budějovice, Czech Republic. Phone: ++420 387775 432; Fax: ++420 385 310 388; E-mail: moravec@paru.cas.cz 
nol. For light microscopy (LM), the nematodes were cleared with glycerine. Drawings were made with the aid of a Zeiss drawing attachment. Specimens used for scanning electron microscopy were postfixed in $1 \%$ osmium tetroxide (in phosphate buffer), dehydrated through a graded acetone series, critical point dried and sputter-coated with gold; they were examined using a JEOL JSM-6300 SEM at an accelerating voltage of $15 \mathrm{kV}$ or a JEOL JSM-7401F at an accelerating voltage of $4 \mathrm{kV}$. All measurements are in micrometres unless otherwise indicated. The names of fishes follow FishBase (Froese and Pauly 2008).

\section{REDESCRIPTION}

Philometra saltatrix Ramachandran, 1973 Figs. 1, 2

Male (10 specimens): Body filiform, whitish, 2.26$2.95 \mathrm{~mm}$ long, maximum width 45-54. Anterior part of body slightly narrower than posterior part; width of cephalic end 27-33, of caudal end 33-39. Cuticle smooth. Cephalic end rounded. Oral aperture circular, very small, surrounded by 14 small cephalic papillae arranged in two circles (Figs. 1B, 2A): external circle formed by four submedian pairs of papillae; internal circle by four submedian and two lateral single papillae; pair of lateral amphids present. Oesophagus 369-561 long, forming $15-21 \%$ of body length, somewhat inflated at anterior end; posterior part of muscular oesophagus overlapped by well developed oesophageal gland with large cell nucleus in middle. Oesophageal nucleus and nerve ring 237-285 and 111-120, respectively, from anterior extremity. Posterior part of oesophagus partly overlapped by anterior end of testis (Fig. 1A). Excretory pore 171-180 from anterior end of body. Posterior end of body blunt, with two broad, lateral lobular mounds curved dorsally, but separated from each other on dorsal side (Fig. 2B, D), and with one pair of adanal and two pairs of postanal very flat, hardly visible caudal papillae (Fig. 1J, K). Spicules slender, needle-like, equal or slightly subequal, with somewhat expanded proximal and sharply pointed distal tips; length of spicules $84-111$, representing $3-5 \%$ of body length (Fig. 1J, K). Gubernaculum narrow, 75-84 long, with approximately its proximal half somewhat dorsally bent; length of anterior bent part 39-45, representing $46-56 \%$ of entire gubernaculum length (Fig. $1 \mathrm{G}$ ); middle of gubernaculum markedly broader, with distinct ventral barb in lateral view; distal end of gubernaculum with two ventral longitudinal grooves (Fig. 2F) and with distinct transverse annulation on dorsal side (Figs. 1H, $2 \mathrm{E}, \mathrm{F}$ ); usual reflected dorsal barb absent. Length ratio of gubernaculum and spicules 1:1.15-1.29. Spicules and gubernaculum well sclerotized; spicules and posterior part of gubernaculum brownish, anterior part of gubernaculum colourless.

Subgravid female (4 complete specimens and many body fragments): Body of fixed specimens brown coloured, with smooth cuticle; body length $36-75 \mathrm{~mm}$, maximum width 231-462; posterior part of body nar- rower than anterior part. Cephalic end rounded, cephalic papillae very small, indistinct when viewed laterally. Oral aperture large, circular to oval (rarely almost triangular), surrounded by four pairs of submedian cephalic papillae of external circle and six single papillae (two lateral and four submedian) of internal circle (Figs. 1C, 2C). Pair of small lateral amphids present. Bottom of mouth formed by three oesophageal sectors. Oesophagus including anterior bulbous inflation $0.72-1.02 \mathrm{~mm}$ long; bulb 82-109 long and 95-109 wide (Fig. 1D). Oesophageal gland well developed; large oesophageal gland nucleus 435-653 from anterior extremity. Nerve ring 204-245 from anterior end of body. Small ventriculus 27-41 long and 54 wide. Oesophagus opening into intestine through distinct valve. Intestine dark brown, ending blindly, its posterior end narrow, attached by long ligament ventrally to body wall near caudal end. Vulva and anus absent. Ovaries long, situated near body ends. Uterus occupying most space of body, filled with numerous eggs. Caudal end rounded, with two very small, hardly visible lateral papilla-like projections (Fig. 1I).

H o s t: Bluefish Pomatomus saltatrix (Linnaeus) (Pomatomidae, Perciformes).

Site of infection: Gonads.

L o c a 1 i t y: Tuscan Sea, off Italy.

Prevale n c e a nd inte n s ity: Total prevalence about $24 \%$ ( $40 \%$ in females and $0.5 \%$ in males); worms per fish not counted (from about 10 specimens in small gonads to many more in bigger ones).

Deposition of voucher specimens: Helminthological Collection of the Institute of Parasitology, Biology Centre of the Academy of Sciences of the Czech Republic, České Budějovice (Cat. No. N-809).

\section{DISCUSSION}

Ramachandran's (1973) description of the male of Philometra saltatrix is very brief and inaccurate. Although the body length and width (2.11-2.70 and 0.04$0.05 \mathrm{~mm}$ ) are similar to those found in the present study, his measurements of internal organs are either erroneous or doubtful. For example, as can be seen from his fig. 4, he considered only the anterior part of oesophagus (anterior to the nerve ring) to be the complete oesophagus and the anterior end of testis (overlapping the posterior part of oesophagus) to be the intestine. He did not mention the length and structure of the gubernaculum, and it is highly probable that, as suggested by his fig. 5 , he measured only incomplete spicules without counting their less-sclerotized proximal tips; this explains why he found the spicules somewhat shorter $(60-70 \mu \mathrm{m})$ as compared to those in the present material $(84-111 \mu \mathrm{m})$. According to Ramachandran (1973), the cuticle of $P$. saltatrix males was covered with microscopic bosses. However, no such formations were observed on the males of the present material, even after SEM observations. Detailed structures of the oesophagus, gubernacu- 

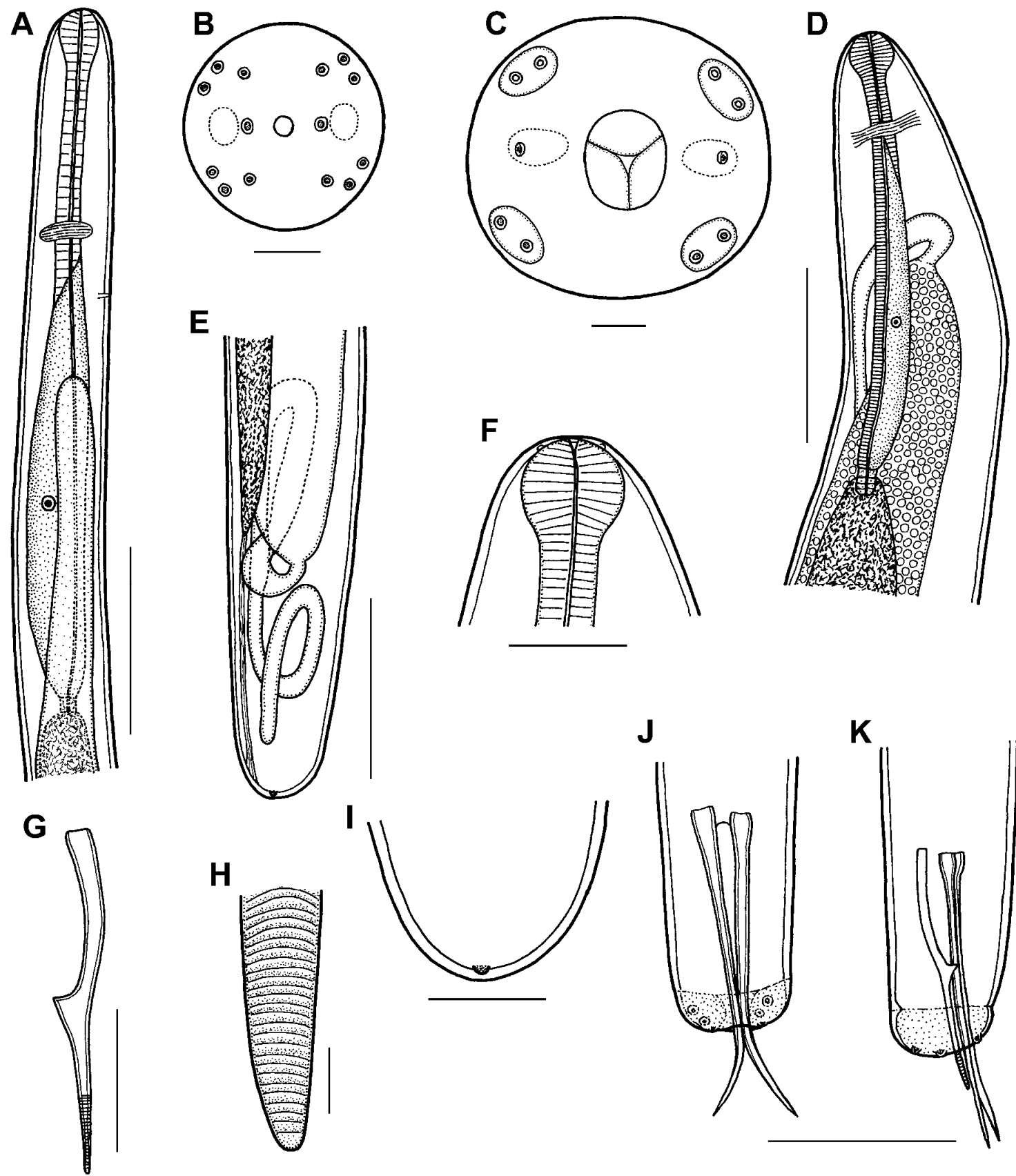

Fig. 1. Philometra saltatrix Ramachandran, 1973. A - anterior end of male, lateral view; B - cephalic end of male, apical view; C - cephalic end of subgravid female, apical view; D, E - anterior and posterior ends of subgravid female, lateral views; $\mathbf{F}$ - cephalic end of subgravid female, lateral view; $\mathbf{G}$ - gubernaculum, lateral view; $\mathbf{H}$ - distal end of gubernaculum, dorsal view; $\mathbf{I}$ - caudal end of subgravid female, lateral view; $\mathbf{J}, \mathbf{K}$ - posterior end of male, ventral and lateral views. Scale bars: A, J, K = 50 $\mu \mathrm{m} ; \mathrm{B}=5 \mu \mathrm{m} ; \mathrm{C}=10 \mu \mathrm{m} ; \mathrm{D}, \mathrm{E}=300 \mu \mathrm{m} ; \mathrm{F}, \mathrm{I}=100 \mu \mathrm{m} ; \mathrm{G}=30 \mu \mathrm{m} ; \mathrm{H}=2 \mu \mathrm{m}$.

lum and cephalic and caudal ends of the male of $P$. saltatrix are described for the first time in this paper.

The morphology of subgravid females of $P$. saltatrix, as found in this study, is in accordance with that described by Moravec and Genc (2004); the only difference is the presence of minute papilla-like caudal projections, which were probably overlooked by these authors. It again confirms that the female oral aperture of $P$. saltatrix is circular to oval (Fig. 1C), although, sometimes, it may appear to be somewhat triangular in shape (Fig. 2C). Unfortunately, the body length of gravid (larvigerous) females of this species remains unknown (they may be up to about $250 \mathrm{~mm}$ long according to some non-documented observations). 

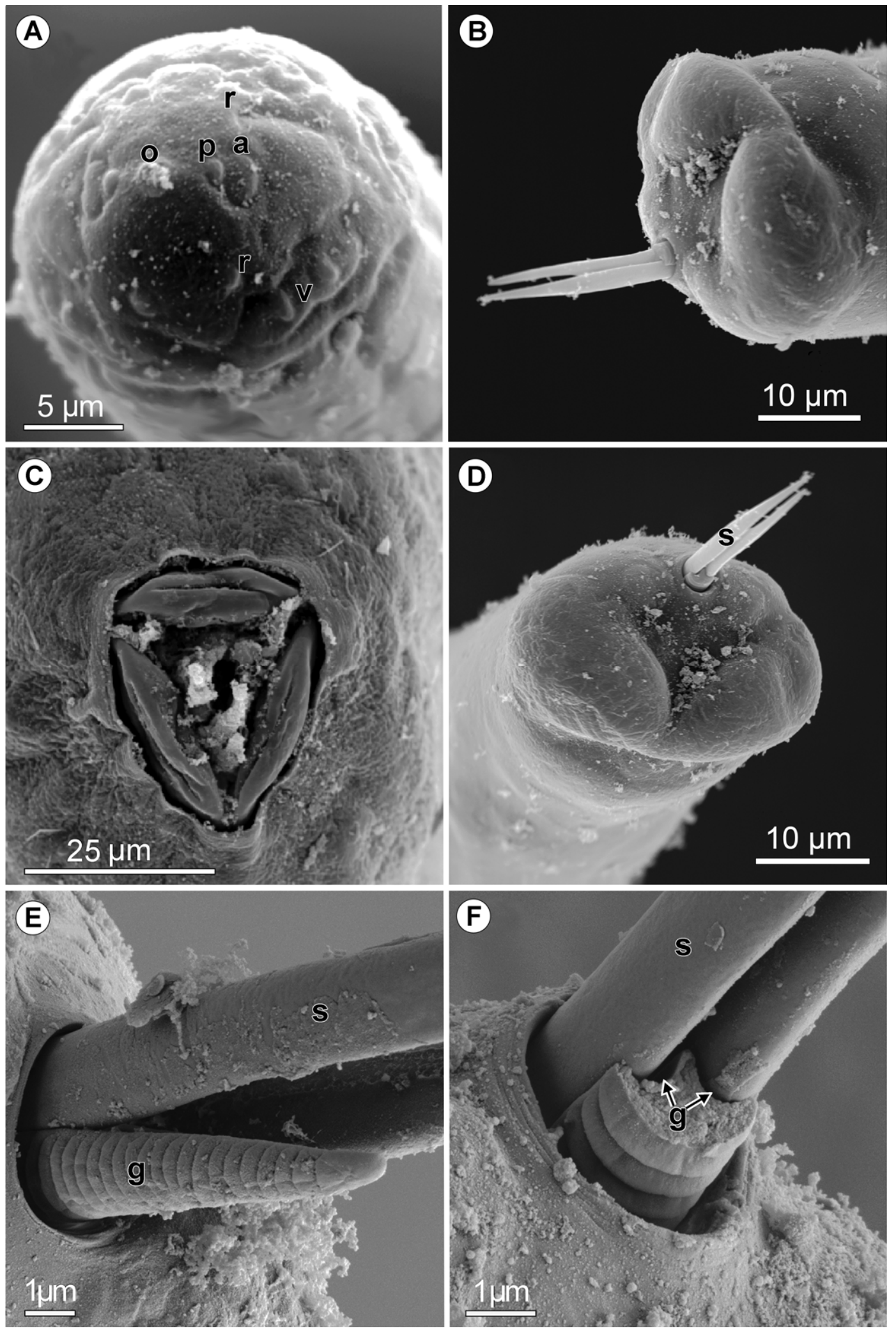

Fig. 2. Philometra saltatrix Ramachandran, 1973, scanning electron micrographs. A - cephalic end of male, apical view; B - caudal end of male, dorsolateral view; C - cephalic end of subgravid female, apical view; D - caudal end of male, apical view; $\mathbf{E}$ - region of cloaca with extruded spicules and gubernaculum, lateral view; $\mathbf{F}$ - same, specimen with incomplete gubernaculum (arrows indicate longitudinal grooves on ventral side of gubernaculum). Abbreviations: a - amphid; g - gubernaculum; $\mathrm{o}$ - oral aperture; $\mathrm{p}$ - lateral cephalic papilla of internal circle; $\mathrm{r}$ - submedian cephalic papilla of internal circle; $\mathrm{s}-\mathrm{spicule} ; \mathrm{v}-$ pair of submedian cephalic papillae of external circle. 
At present, there are known 21 gonad-infecting species of Philometra parasitizing marine and brackishwater fishes (for key see Moravec et al. 2008). Recently, Quiazon et al. (2008) redescribed Philometra lateolabracis (Yamaguti, 1935) from the type host and described two new congeneric gonad-infecting species from marine fishes from Japanese waters. Based on SEM study, they found, for the first time in Philometra, the distal part of the gubernaculum of $P$. lateolabracis and P. madai Quiazon, Yoshinaga et Ogawa, 2008 to bear dorsal transverse lamella-like structures. Similar structures on the gubernaculum are now reported for the first time in the male of $P$. saltatrix. In contrast to $P$. lateolabracis and P. madai, the oral aperture of the female of $P$. saltatrix is usually circular to oval instead of triangular and the dorsal protuberance on the distal end of the gubernaculum is absent.

According to available data, Philometra saltatrix seems to be a specific parasite of the bluefish, Pomatomus saltatrix, throughout the distribution area of this fish. It has been reported from the Northwest Atlantic off the coast of the USA (Ramachandran 1973, Cheung et al. 1984, Clarke et al. 2006, Moravec et al. 2008), where also the previous records of Philometra globiceps (Rudolphi, 1819) from P. saltatrix by Linton (1901, $1905)$ and Walton (1928) represented probably misidentified P. saltatrix (see Moravec 2006). The records of this parasite from $P$. saltatrix in the Iskenderun Bay, Turkey (Moravec and Genc 2004) and in the Tuscan Sea, Italy (present study) indicate that it is also widespread in the region of the Mediterranean Sea. From the Mediterranean region, an additional four gonadinfecting species of Philometra have been reported: $P$. globiceps, P. filiformis (Stossich, 1896), P. jordanoi (López-Neyra, 1951) and P. serranellicabrillae Janiszewska, 1949 (see Moravec 2006, 2008).

Acknowledgements. Our thanks are due to the Laboratory of Electron Microscopy, Institute of Parasitology, Biology Centre of the ASCR, Ceské Budějovice for technical assistance, and Irena Husáková and Blanka Škoríková, Department of Helminthology at the same Institute, for help with illustrations. We also wish to thank the staff of the Laboratory of Parasitology, Veterinary Faculty, Pisa. This study was partly supported by the grant 524/06/0170 from the Grant Agency of the Czech Republic and by the research projects of the Institute of Parasitology, ASCR (Z60220518 and LC522).

\section{REFERENCES}

Cheung P.J., Nigrelli R.F., RugGieri G.D. 1984: Philometra saltatrix infecting the heart of the 0-class bluefish, Pomatomus saltatrix (L.), from the New York coast. In: S.F. Snieszko commemoration fish disease workshop. Joint Workshop of Fish Health Section, AFS, and Midwest Disease Group, Little Rock, AR, p. 27.

Clarke L.M., DOve A.D.M., CONOver D.O. 2006: Prevalence, intensity, and effect of a nematode (Philometra saltatrix) in the ovaries of bluefish (Pomatomus saltatrix). Fish. Bull. 104: $118-124$.

Froese R., PAUly D. (Eds.) 2008: FishBase. World Wide Web electronic publication, www.fishbase.org, 03/2008.

HINE P.M., ANDERSON C.D. 1982: Diseases of the gonads and kidneys of New Zealand snapper, Chrysophrys auratus Forster (F. Sparidae). In: M.E. Fowler (Ed.), Wildlife Diseases of the Pacific Basin and Other Countries. Academic Press, London, pp. 166-170.

LiNTON E. 1901: Parasites of fishes of the Woods Hole Region. Bull. U.S. Fish. Comm. 1899: 441-481.

LINTON E. 1905: Parasites of fishes of Beauforty North Carolina. Bull. Bur. Fisher. (1904), 24: 321-428.

MORAVEC F. 2004: Some aspects of the taxonomy and biology of dracunculoid nematodes parasitic in fishes: a review. Folia Parasitol. 51: 1-13.

MORAVEC F. 2006: Dracunculoid and Anguillicoloid Nematodes Parasitic in Vertebrates. Academia, Prague, 634 pp.

MORAVEC F. 2008: Systematic status of Philometra jordanoi (López-Neyra, 1951) and some other congeneric species previously identified as Philometra lateolabracis (Yamaguti, 1935) (Nematoda: Philometridae). Folia Parasitol. 55: 159160.

MorAVEC F., DE BURON I., BAKER T.G., GONZÁLEZ-SOLÍS D. 2008: Some gonad-infecting species of Philometra (Nema- toda: Philometridae) from offshore fishes of South Carolina and Georgia, USA, including Philometra charlestonensis sp. $\mathrm{n}$. from the scamp Mycteroperca phenax. Acta Parasitol. (In press.)

MORAVEC F., GENC E. 2004: Redescription of three Philometra spp. (Nematoda, Philometridae) from the gonads of marine perciform fishes of Iskenderun Bay (North-East Mediterranean), Turkey. Acta Parasitol. 49: 31-40.

MoraVEC F., SALGADO-MALdONADO G. 2007: A new species of Philometra (Nematoda, Philometridae) from the gonads of the rock hind Epinephelus adscensionis (Osteichthyes) from the southern Gulf of Mexico. Acta Parasitol. 52: 376-381.

QUiAZON K.M.A., Yoshinaga T., Ogawa K. 2008: Taxonomical study into two new species of Philometra (Nematoda: Philometridae) previously identified as Philometra lateolabracis (Yamaguti, 1935). Folia Parasitol. 55: 29-41.

RAMACHANDRAN P. 1973: Philometra saltatrix sp. n., infecting the gonads of the common bluefish Pomatomus saltatrix (L.) of the New England Coast of the United States. Zool. Anz. 191: 325-328.

RAMACHANDRAN P. 1975: Philometra cephalus sp. n. infecting the gonads of the striped mullet, Mugil cephalus L. from the Arabian coast of Kerala, India, with a note on its pathology. Zool. Anz. 194: 140-144.

RASHEED S. 1963: A revision of the genus Philometra Costa, 1845. J. Helminthol. 37: 89-130.

SAKAGUCHI S., YAMAGATA Y., SAKO H. 1987: Reidentification of Philometra parasitic on the Red Sea bream. Bull. Nat. Res. Inst. Aquacult., No. 12, 69-72. (In Japanese, English summary.)

WALTON A.C. 1928: A revision of the nematodes of the Leidy collections. Proc. Acad. Nat. Sci. Philadelphia 79: 49-163+ Plts. 4-10. 